\title{
ABSOLUTE VISUAL SENSITIVITY OF THE GOLDFISH
}

\author{
Malreen K. Powers ${ }^{1.2}$ \\ Department of Psychology, Lniversity of Michigan. Ann Arbor. MI 48109 . U.S.A \\ and \\ STEPHEN S. EAster JR \\ Department of Experimental Biology. Division of Biological Sciences. Liniversity of Michigan. \\ Ann Arbor. Ml 18109 . L.S.A.
}

(Receited 21 Occober 1977 : in recised form 4 December 1977)

\begin{abstract}
Absolute visual threshold was measured in dark-adapted goidfish, using classical conditioning of heart and respiration rates. For threshold detection of a $132^{2}$ diameter stimulus near the peak of the rod pigment's sensitivity, only I quantum was incident for every $2000-4000$ rods, and $400-830$ photoisomerizations were needed for vision. Spectral sensitivity was also determined at absolute threshold. using respiration rate conditioning. The shape of the function matches the electrophysiologically determined spectral sensitivity of goldfish retinal ganglion cells, but both curves are relatively more sensitive in the long wavelengths than would be predicted on the basis of the rod pigment alone. A dim $703 \mathrm{~nm}$ background depressed sensitivity to a $636 \mathrm{~nm}$ test light more than to a $532 \mathrm{~nm}$ test. proving that another class of photoreceptors is active at absolute threshold. If the other teceptors were the red cones, as seems most likely, then only 1 quantum was incident per 220 red cones at their absolute threshold, and photoisomerizations occurred in each of 164 red cones at threshold.
\end{abstract}

Key Words-goldfish: absolute threshold; spectral sensitivity; classical conditioning: retina: retinomotor movements.

\section{INTRODUCTION}

Absolute visual threshold is the smallest amount of light that can be detected but that amount varies with the detector's location in the visual system. While 1 quantum of light is sufficient to excite a rod (Hecht, Shlaer and Pirenne, 1942; Fain, 1975) and perhaps a cone (Baylor and Hodgkin, 1973; Schwartz, 1975), vision does not occur unless several receptors are excited (Hecht et al., 1942). Electrophysiologists (e.g. Fain, 1975) can gather direct evidence for thresholds of individual rods and cones, but they cannot tell at what intensity the signal is visible. Psychophysicists. on the other hand. can provide only indirect evidence about single receptor thresholds, but they are uniquely able to define the absolute threshold for seeing (e.g. Hecht et al. 1942). This paper reports psychophysical measurements of the absolute threshold of rods and cones in the goldfish; preliminary reports have appeared elsewhere (Powers and Easter. 1975a.b; Powers. 1976).

The goldfish is particularly well suited for this study because its visual system has been studied so extensively. The photopigments in both rods (Schwanzara, 1967) and cones (Marks. 1965) are known. as are the spectral sensitivities of elements at nearly every level of visual processing (e.g. Wagner, MacNichol and Wolbarsht. 1960; Yager. 1967, 1968;

${ }^{1}$ Submitted in partial fulfillment of the requirements for the degree Doctor of Philosophy in Psychology at the University of Michigan.

'Current address: Department of Psychology, NI-25. University of Washington. Seattle, Washington 98195. U.S.A.
Kaneko, 1973). The absolute rod threshold has been estimated from the responses of retinal ganglion cells (Raynauld, 1969), and measurement of the absolute threshold of red-sensitive cones should be possible because their wavelength of peak sensitivity-625 nm (Marks, 1965; Liebman and Entine, 1964; Tomita, Kaneko. Murakami and Pautler, 1967)-is so much longer than that of rods- $-522 \mathrm{~nm}$ (Schwanzara. 1967)-that the two mechanisms overlap very little. Finally, the goldfish can easily be trained, using a classical conditioning paradigm, to slow its heart and respiration rates in response to a visual stimulus (Otis, Cerf and Thomas. 1957).

\section{METHODS}

The techniques for conditioning heart and respiration rate were modified from Hester (1968) and Vorthmore and Yager (1975), respectively.

\section{Subjects and surgery}

The goldfish (Carassius auratus: Ozark Fisheries) were 12-14 cm long. tip-to-tip. Five fish were satisfactory heart rate subjects. They only participated in one experiment: absolute threshold at $538 \mathrm{~nm}$. Seven different fish were res. piration rate subjects, and all of them participated in more than one experiment. Three untrained fish provided eyes for the histological examinations of retinomotor state.

Electrocardiograms were recorded with chronically implanted fine silver wire electrodes. They were inserted ventrally in anesthetized fish to lie rostral and caudal to the heart, and were anchored to the abdominal skin with surgical silk. The exposed leads were glued together and attached to a piece of styrofoam so that they would float out of the fish's way. 


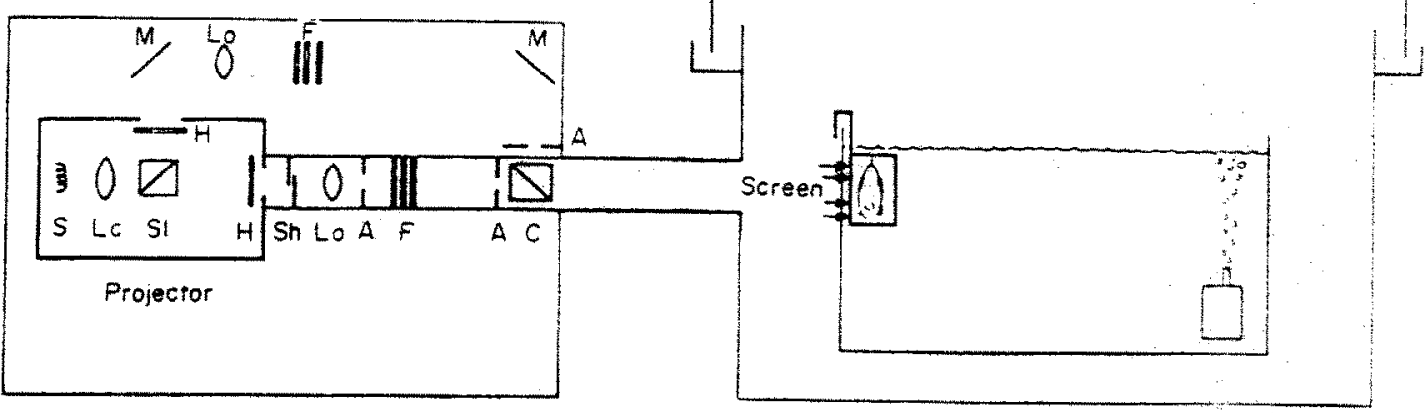

Fig. 1. Classical conditioning apparatus. S: source; $L_{c}$; condenser lens; Sl: microslide beamsplitter: $H$ : heat flter; Sh: electronically activated shutter: $L_{0}$ : objective lens: $A$ : aperture; $F$ : neutral density and monochromatic filters; $\mathrm{C}$ : recombining cube; $\mathrm{M}$ : mirtor. Images of the filament were focused on Sh. $\mathrm{H}$ (but only in the upper beam) and on the entry side of $C . S$ and $L$, were parts of a Leitz Pradolux projector.

\section{Apparatus}

Figures 1 and 2 show the apparatus. The fish was restrained in a small plastic box suspended from the side of a water-filled aquarium. isolated from non-stimulus light. The right eye faced a diffusing rear projection sereen. During measurements of respiration rate. pieces of sponge were packed around the fish to minimize head and body movements. Packing with sponges was impractical during heart rate measurements because of the danger of dislodging the EKG leads. Presentation of the light was initiated by the experimenter. The fish was shocked $(4-8 \mathrm{~V} \mathrm{a.c.)}$ at the offset of the light via two copper grid electrodes near its tail.

The EKG was preamplified (Tektronix 122) and either recorded on paper (Techni-Rite TR722) or displayed on a storage oscilloscope (Tektronix 564B) where it could be photographed. Typical QRS wave amplitudes were $0.1-0.5 \mathrm{mV}$.

Respiration rate was monitored by a thermistor (Thermometrics P60DA202M) positioned anterior to the animal's mouth and operated in the self-heating mode in a voltage divider circuit. The pocket of warm water surrounding the tip of the thermistor was displaced by cooler water whenever the fish drew water into its mouth. The resulting voltage changes were rhythmic and generally about $20-50 \mathrm{mV}$-big enough to go directly to the recording device without preamplification.

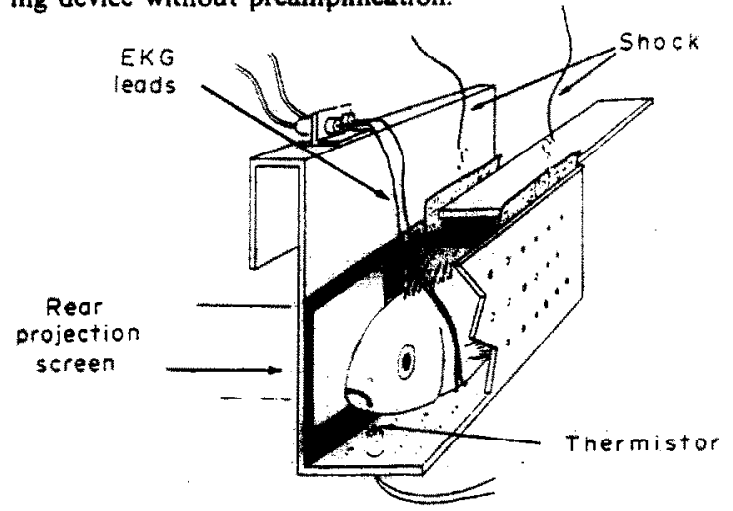

Fig. 2. Cutaway view of a fish in the restraining box. The right eye was always toward the screen. Thermistor and EKG electrodes are both shown, but only one was used in any given experiment. The lid covered the box during testing Holes eased water circulation through the box. which was black and opaque except for the sereen fa piece of bond paper glued to the outside). The shock grids were copper mesh, and were held away from the fish's tail by plastic inserts (not visible). The fish was completely enclosed during testing.

\section{Stimulus}

The stimulus (lower channel in Fig. 1) was a circular field which subtended $132^{\circ}$ visual angle: the background (upper channel in Fig. 1). when present, was slightly larger and approximately square. The stimulus screen was less than $1 \mathrm{~cm}$ from the center of the fish's lens, and therefore probably out of focus, because these tish have lenses of focal length approximately $7 \mathrm{~mm}$ (calculated from Easter, Johns and Baumann, 1977).

The stated stimulus diameter was calculated on the assumption that the eye was in one position throughiout the experiments. Because head movements were restricted by the sponges in the respiration rate studies, and because eye movements (Easter, 1971) are small relative to the size of the visual field (Easter et al., 1977). this assumption is reasonable for those experiments. But side-to-side head movements could have changed the size of the retinal image by as much as $\pm 20^{\circ}$ during the heart rate experiment. wherein head movements were less stringently controlled.

Irradiance was measured for each wavelerigth with the screen in place, but with no water, using a radiometrically calibrated, spectrally flat photodiode (United Detector Technology PIN-10DF). The measured value varied $\pm 0,12$ $\log$ units (at $532 \mathrm{~nm}$ ) during the course of the experiments. which spanned 28 months. This amount of variation is smaller than we find between subjects (see below) and could have been due to changes in absolute and/or spectral emission of the bulb (24V, $120 \mathrm{~W}$ quartz-halogen) over time, or to small differences in the relative positions of the source and screen.

We measured the uniformity of the stimulus in two ways. In the first, the stimulus screen was traversed along two orthogonal axes with a photodiode masked by an aperture one-tenth the diameter of the stimulus. In the second, the stimulus screen was traversed by the same aperture, with the photodiode, in water. at the plane of the fish's pupil. Both measurements showed that the energy was nearly constant over the central $60^{\circ}$ and decreased peripherally until. at the limit it was about 10-fold lower than at the center. These measurements were used to compute the ratio (intensity in the center/average intensity over the entire stimulus). which had a value of about 2 .

\section{Computation of retinal stimulus}

The number of incident quanta per receptor in $1 \mathrm{sec}$ at threshold. $T_{i}$, was calculated according to the following formula:

$$
T_{i}=\frac{l_{i} A_{p} t_{i} P}{F_{i} A_{s} n}
$$

where:

$I_{\lambda}=$ unattenuated stimulus irradiance at the plane of the pupil, in $q / \mathrm{sec}$ per $\mathrm{cm}^{2}$ 
$A_{p}=$ area of the entrance pupil, in $\mathrm{cm}^{2}$

$t_{i}=$ transmission of the ocular media (Burkhardt. 1966)

$p=$ proportion of retinal surface occupied by receptors

$F_{i}=$ attenuation by neutral density filters at threshold

$A_{s}=$ area of the stimulus on the retina, in $\mathrm{cm}^{2}$

$n=$ number of receptors in $1 \mathrm{~cm}^{2}$ of retina.

$l_{\alpha}$ was calculated by dividing the most recent calibration value, in erg; sec per $\mathrm{cm}^{2}$, by the energy (in erg/q) in light of wavelength 2 .

$A_{p}$ was measured in several subjects. Its value varied very little; the mean. $0.096 \mathrm{~cm}^{2}$, was used throughout.

$A$, is best represented. especially for large stimuli. as the partial area of a spherical surface, which the goldfish's retina approximates (Charman and Tucker. 1973). Hence

$$
A_{s}=\int_{0}^{6 \theta} 2 \pi r^{2} \sin \theta \mathrm{d} \theta=3.72 r^{2}
$$

where $r$ is the radius of the sphere. The value of $r$ was computed as follows: We know that the retina of the goldfish subtends $185^{3}$ with respect to the center of the lens (Easter et al., 1977), and that the corresponding distance along the arc-the retinal length $L$-can be inferred from body length (Easter et al.. 1977). Thus

$$
r=\frac{360^{\circ}(L)}{185^{\circ}(2 \pi)}
$$

$A$, was calculated using the average body length; the mean, $0.42 \mathrm{~cm}^{2}$, was used throughout.

For receptor surface densities $(n)$, we used the following rods, $1.44 \times 10^{7} / \mathrm{cm}^{2}$ (Schellart, 1973); and red-sensitive cones. $5.0 \times 10^{5} / \mathrm{cm}^{2}$ (calculated from Stell and Harosi, 1976. The number of rods and red cones in the stimulus patch, then, was $6.0 \times 10^{6}$ and $2.1 \times 10^{5}$, respectively. The assumption of constant receptor densities is based on reports by Stell and Harosi (1976) and Johns and Easter (1977). This uniformity is disputed by others (Hester. 1968; Schellart, 1973; Marc and Soerling. 1976). Even in the latter reports. however, the range is small (on the order of 2-3 fold), and we believe that our conclusions are no materially affected by utilization of an average number.

We assume, on the basis of histological observations, that rod outer segments completely cover the retinal surface. i.e. $p=1$.

To estimate $p$ for red cones, we need to know the capture area of one red cone. We have assumed that the largest cross-sectional area of a cone's outer segment. i.e. the area at its base, is its effective capture area. Averaging the four values listed by Stell and Harosi (1976) for the dianteter of red cone outer segments at the base, and cor- recting for their estimate of shrinkage during histologica! preparation. we obtain a mean capture area per red cone of $3.0 \times 10^{-7} \mathrm{~cm}^{2}$. When this is multiplied by the surface density, given above. it yields $p=0.15$.

$T_{i}$ represents the ratio of incident quanta to receptors in $1 \mathrm{sec}$ at absolute threshold. There were many more quanta in the 5 or $10 \mathrm{sec}$ stimulus but since the fish generally responded within the first second of the sumulus (cf. Fig. 3). the number in $1 \mathrm{sec}$ is an upper estimate of the number of incident quanta that contributed to the response.

The effective $T_{i}$ is increased slightly by the tapetum lucidum. If it reflected all of the incident light not absorbed on the first pass through the retina, then it would increase the effective $T_{i}$ by $50 \%$. This follows from out assumption that half of the incident light is absorbed by the photopigment on the first pass (see Results). But the tapetum in goldfish is restricted to the dorsal hemiretina (cf. Siell and Hárosi, 1976), and the stimulus covered roughly equal areas of dorsal and ventral hemiretinas. Therefore the overall effect of the tapetum would be to increase the photon flux through the outer segment layer by only about $25 \%$ or approximately $0.1 \mathrm{log}$ unit. We have ignored this small correction in our later analyses.

\section{Procedures}

The procedures used for heart rate conditioning will be presented first, followed by the ways in which respiration rate conditioning differed.

\section{Heart rate conditioning}

Fish were dark-adapted $0.5-5 \mathrm{hr}$ in their home tanks. and at least $10 \mathrm{~min}$ in the test box. Each animal had at least one (usually two) $30-40 \mathrm{~min}$ habituation sessions in the apparatus in the dark with no stimulus before its first training session. The conditioned stimulus was a spot of light which lasted $10 \mathrm{sec}$. During training, its intensity was 3-5 log units above absolute threshold. The unconditioned stimulus, delivered at the offset of the light, was tail shock of $0.1 \mathrm{sec}$ duration. Its amplitude was adjusted for each fish in each session so that the fish wiggled when shocked. The unconditioned response was a decrease in heart rate. With sufficient pairings of light and shock, heart rate deceleration became a conditioned response to the light (Fig. 3).

The mean interbeat interval was calculated from three randomly selected values (measured from QRS wave to QRS wave) from every intertrial interval. The time between the QRS wave closest to light onset and the next QRS wave was recorded. When that interval was at least 2 standard deviations longer than the mean, a response was scored.
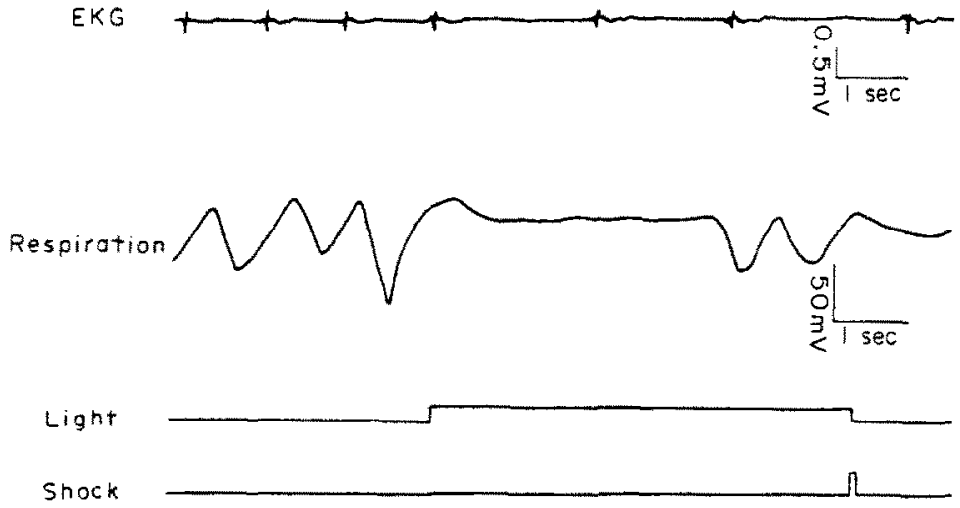

Fig. 3. Sample EKG and respiration records from conditioned fish. Recordings from two different conditioned fish are shown, with indications of the duration of light and shock below. Note that interbeat and interbreath intervals are longer following light onset. 
Training sessions were either 10 or 20 trials. The intertrial interval averaged $1.5 \mathrm{~min}$. Shock occurred on every trial. Fish were always trained during daylight hours, and often more than once per day. They were trained until they responded to at least $80 \%$ of the stimulus presentations for two consecutive sessions.

We used the following procedure to find threshold in the trained animals. The initial intensity for a test was the same as the training intensity. If the animal responded. the intensity was decreased for the next trial; if not, it was increased. The intensity steps well above threshold were 0.2 and $0.3 \log$ units; they were $0.1 \log$ units close to threshold. Tests were always 20 trials. with one or two additional randomly inserted catch trials. On catch trials the stimulus beam was blocked before the recombining cube and the fish were not shocked: all other conditions remained the same.

Subjects were tested until the stimulus intensity oscillated around the same value for two sessions. Psychometric functions were drawn for each fish, and threshold was defined as the intensity that produced a response $50 \%$ of the times it was presented. Unless one of the intensities tested happened to be at threstiold, the value was obtained by graphically interpolating between the two $\log$ intensities that bracketed $50 \%$ response. In one case (see Fig. 4) the frequency-of-seeing curve crossed the $50 \%$ line more than once. The lowest value was the one used.

\section{Respiration rate conditioning}

The procedure was the same as described for heart rate conditioning. with the following exceptions: (1) light duration was $5 \mathrm{sec}$; (2) the response was a decrease in respiration rate (Fig. 3); (3) intensity steps in the staircase were always 0.2 or $0.3 \mathrm{log}$ units; and (4) the criterion for response was that the number of breaths in the CS-US interval had to be half (or less) of the ongoing rate. The ongoing rate was defined as the mean number of breaths in six randomly selected $5 \mathrm{sec}$ nonstimulus intervals; it was recalculated before each trial. Statistical analysis of the results showed that this was approximately as demanding a response criterion as the one used in heart rate conditioning.

\section{Retinal histology}

Untrained fish, exposed to background and test stimuli comparable to those encountered by trained subjects, were enucleated as rapidly as possible following the exposure. and their eyes fixed in AFA (ethyl alcohol, formalin and glacial acetic acid). The eyes were later embedded in paraffin, cut at $10 \mu \mathrm{m}$. mounted on microscope slides and stained with hematoxylin and eosin.

\section{RESULTS}

The animals who became reliable subjects showed some conditioning of heart or respiration rate by the second training session. Only $10 \%$ of the EKG fish became good subjects ( 53 were implanted with electrodes); most of the failures were due to poor implants or to ill health following surgery. In contrast. we had about $70 \%$ success in conditioning respiration rate. $\mathrm{A}$ few trained fish from both paradigms did not perform during threshold testing and were dropped from the experiments at that point.

\section{Rod threshoid}

Absolute thresholds were determined with interference filters of peak transmission ( $532 \mathrm{~nm} .538 \mathrm{~nm}$ ) close to the $i_{\max }$ of goldfish porphyropsin $(522 \mathrm{~nm}$, Schwanzara, 1967). This spectral proximity, the retinomotor state (see below), and the very low

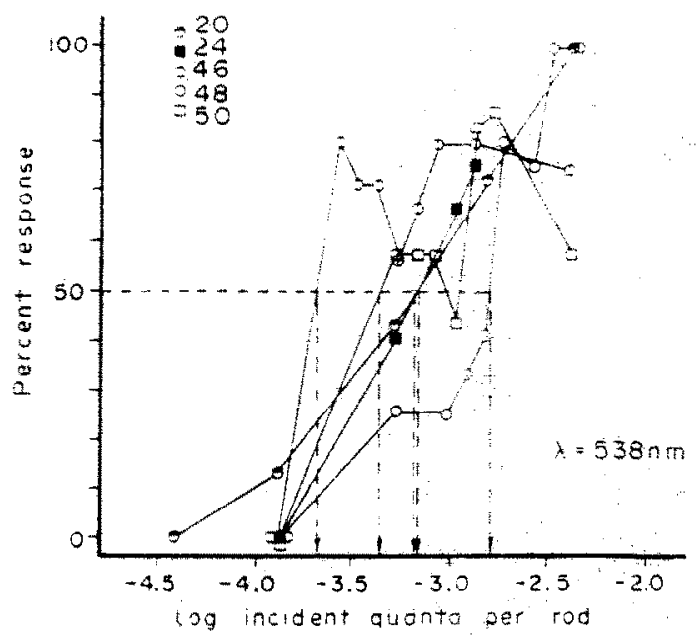

Fig. 4. Absolute visual threshold by heart rate condition. ing. Psychometric functions for individual fish are shown. with the interpolated threshold indicated for each by a dotted line. Ordinate: percent of trials on which heart rate. was at least 2 standard deviations slower than the nonstimulated rate: See Methods for explanation of the abscissa.

thresholds about to be described lead us to belfeve that the rods were the photoreceptors that mediated the threshold response.

The psychometric functions for the heart rate animals are plotted in Fig. 4. The range of values is about 1 log unit. and the mean $\log$ threshold is -3.25 $\log q / \mathrm{sec}$ per rod incident; that is, only 1 quantum was incident per sec per 1800 rods. on the average, at threshold. This corresponds to about $37,000 \mathrm{q} / \mathrm{sec}$ per $\mathrm{cm}^{2}$ at the cornea.

The results of the corresponding respiration rate experiment are shown in Fig. 5. The absolute threshold using this paradigm was $-3.58 \mathrm{log} \mathrm{q} / \mathrm{sec}$ per rod incident, or 1 quantum incident per 3800 rods in $1 \mathrm{sec}$.

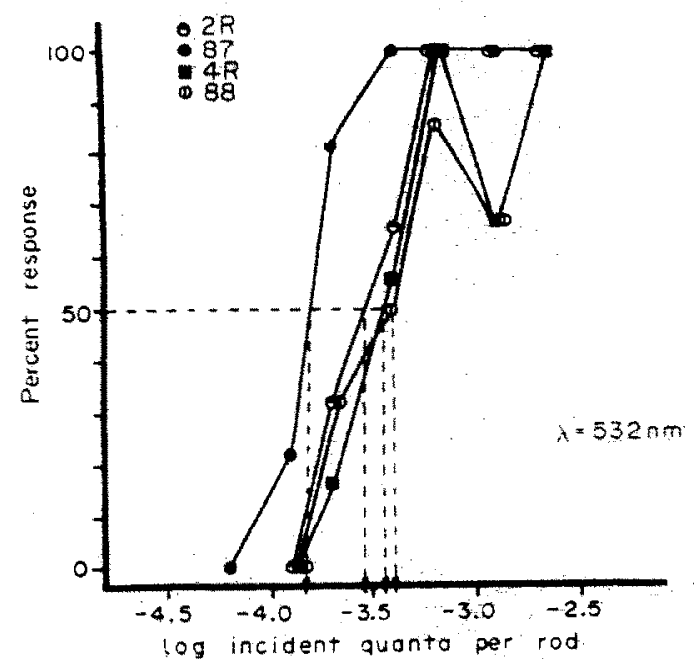

Fig. 5. Absolute visual threshold by respiration rate conditioning. Psychometric functions for four individual animals and their interpolated thresholds are shown, as in Fig. 4. Data for the other subjects are omited. for clatity, but they fell within the range of the plotted functions. Ordinate: Percent of trials on which respitation rate was half the nonstimuluted rate or less. See Methods for explanation of abscissa. 
Table 1. Absolute visual threshold*

\begin{tabular}{|c|c|c|c|c|c|c|}
\hline $\begin{array}{l}\text { Experimental } \\
\text { paradigm }\end{array}$ & $N$ & $i_{\max }$ & $\begin{array}{c}\text { Rods per } \\
\text { incident } \\
\text { quantum } \\
\left(1 / T_{i}\right)\end{array}$ & $\begin{array}{l}\text { Rods per } \\
\text { effective } \\
\text { quantum }\end{array}$ & $\begin{array}{l}\text { Rods receiving } \\
\text { at least } 1 \\
\text { effective } \\
\text { quantum }\end{array}$ & $\begin{array}{c}\text { Rods receiving } \\
2 \text { effective } \\
\text { quanta }\end{array}$ \\
\hline $\begin{array}{l}\text { Heart rate } \\
\text { Respiration } \\
\text { rate }\end{array}$ & $\begin{array}{l}5 \\
7\end{array}$ & $\begin{array}{l}538 \\
532\end{array}$ & $\begin{array}{l}1800 \\
3800\end{array}$ & $\begin{array}{r}7200 \\
15000\end{array}$ & $\begin{array}{l}830 \\
400\end{array}$ & $\begin{array}{l}0.12 \\
0.03\end{array}$ \\
\hline
\end{tabular}

* All values refer to the first second of stimulus.

Because the porphyropsin exists in finite density in the outer segments. the probability that an incident quantum at $\lambda_{\max }$ will be absorbed is only about 0.25 (rudd: Denton, Muntz and Northmore, 1971) to 0.5 (trout: Crouzy and Ali. 1965). In addition, only about 0.5 of the absorbed quanta isomerize a molecule of visual pigment (Kropf, 1967). These two factors combine to limit the number of effective quanta to 1 in every 48 incident. Assuming, for purposes of discussion, that 1 in 4 incident quanta is effective, we calculate that $400-830$ porphyropsin molecules were photoisomerized in the first second, at threshold. This corresponds to a quantum/rod ratio of $1 / 7200$ $1 / 15000$, and indicates that the vast majority of rods received no quanta, and that a very small fraction received 1 or more. We can compute the number of rods that received two effective hits by squaring the probability of one hit and multiplying that by the number of rods in the stimulated area. This number turns out to be $0.03-0.12$; that is, on most trials, there were no double hits. These numbers are summarized in Table 1.

Our threshold measurements are remarkably consistent in several respects. First, two different techniques gave thresholds that differed by only a factor of 2 . Second, even though different subjects were used in the heart rate and respiration rate experiments, the variability between subjects in either paradigm was larger than the differences in mean threshold between the paradigms. Third, the heart and respiration rate experiments were separated by 7 months and still

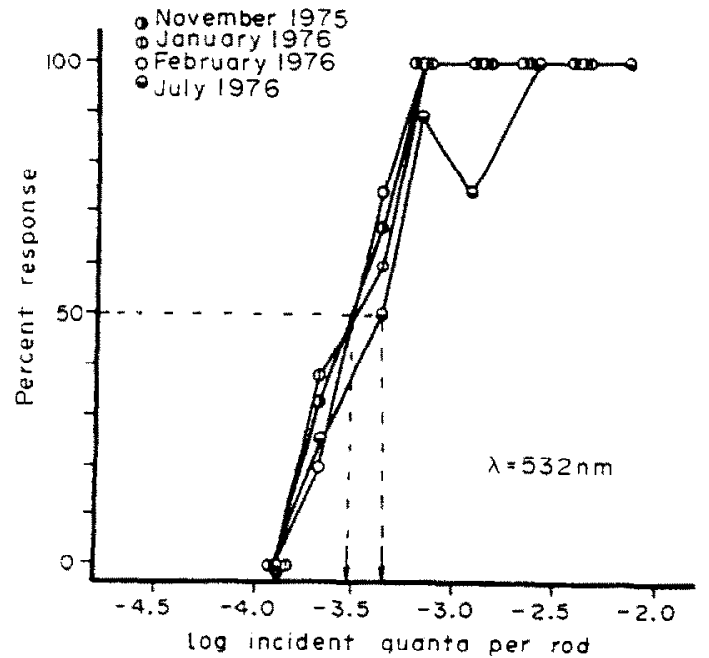

Fig. 6. Reliability of thresholds for one respiration rate conditioning fish. Psychometric functions for one subject (No. 2R), repeated over time. Axes same as in Fig. 5. gave similar results. Fourth, the seven subjects in the respiration rate experiment were actually tested in two groups $(N=4$ and $N=3)$, separated by 5 months; but the mean thresholds of the two groups differed by only $0.01 \mathrm{log}$ units (Powers. 1977). Finally. the variability within subjects was very low. even over long periods of time. Figure 6 shows that threshold for one subject varied only $0.15 \mathrm{log}$ units in four tests over 245 days. a difference that could be due to changes in the source alone (see Methods). Two other fish gave similarly reliable thresholds in two tests over 91 days.

\section{Spectral sensitivity at absolute threshold}

The spectral sensitivity at absolute threshold is shown in Fig. 7. The smooth curves are those of a porphyropsin of $\lambda_{\max }=522 \mathrm{~nm}$ in low and high density (Bridges, 1967). Neither one fits the data; if the curves are shifted so the short wave ends coincide. the long wave ends do not. and vice versa. This suggests that more than one receptor mechanism operates at threshold. We did a chromatic adaptation experiment nexh to test that possibility.

Preliminary experiments had shown that a background of $703 \mathrm{~nm}$ did not influence threshold for a $532 \mathrm{~nm}$ test unless the intensity of the background was more than $1.5 \mathrm{log}$ units above its own absolute

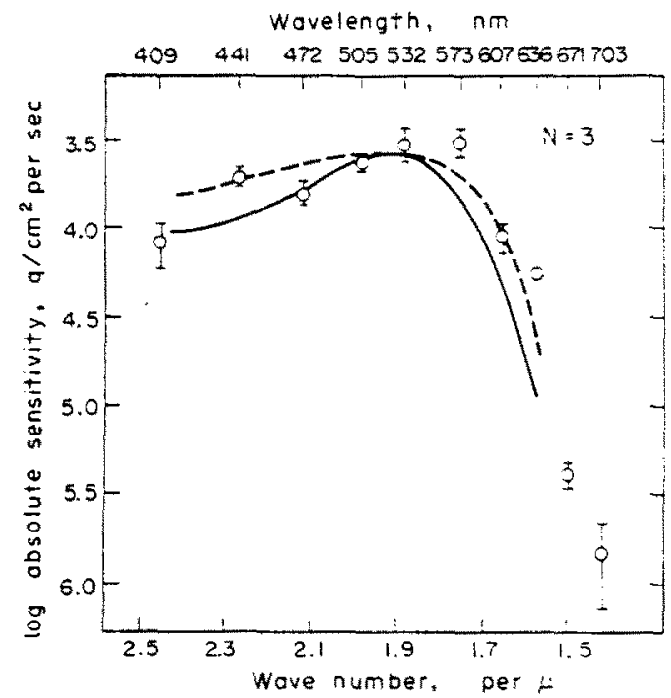

Fig. 7. Spectral sensitivity at absolute threshold, expressed in terms of retinal illumination. The points represent mean $\log$ threshold for three fish; the bars are \pm 1 S.E.M. The smooth curve is a porphyropsin extinction spectrum with peak sensitivity at $i=522 \mathrm{~nm}$, and the dashed curve is the absorption spectrum of the same porphyropsin at density 0.99 . The curves were calculated from Bridges (1967). 
threshold (Powers, 1977). We therefore measured in crement thresholds for both $532 \mathrm{~nm}$ and $636 \mathrm{~nm}$ tests on such a background $(703 \mathrm{~nm} .1 .5 \mathrm{log}$ units above its threshold). We found that although the threshold for the midspectral wavelength light was unaffected, that for the long wavelength light was increased an average of $0.56 \mathrm{log}$ units. Figure 8 shows the relation between the results of this experiment and spectral sensitivity at absolute threshold.

There are two possible explanations for the result in Fig. 8. One is that there were two (or more) receptor mechanisms operating at absolute threshold. The other is that the imposition of the red background changed some characteristic of light transmission through the retina. If retinomotor movements, which are common in fish. occurred as a result of the presence of the background. the latter explanation is not unlikely. For example, the granules in the pigment epithelium might have moved vitreally to shield the rods, thus changing their apparent spectral sensitivity. Or the rod outer segments might have migrated sclerally, thus lengthening the myoid and changing its spectral properties as a light guide (Miller and Snyder, 1972).

We carried out two experiments to test for the presence of such retinomotor phenomena. The first was behavioral. Threshold was tracked following removal of the $703 \mathrm{~nm}$ background used in the previous experiment to see how long it would take to return to its absolute value. For all three subjects, threshold returned to absolute values within $12 \mathrm{~min}$ after the background was turned off (Powers. 1977). This timecourse of recovery is 3-5 times shorter than retinomotor dark adaptation (Ali. 1975). It is therefore unlikely that the chromatic adaptation of the last experiment

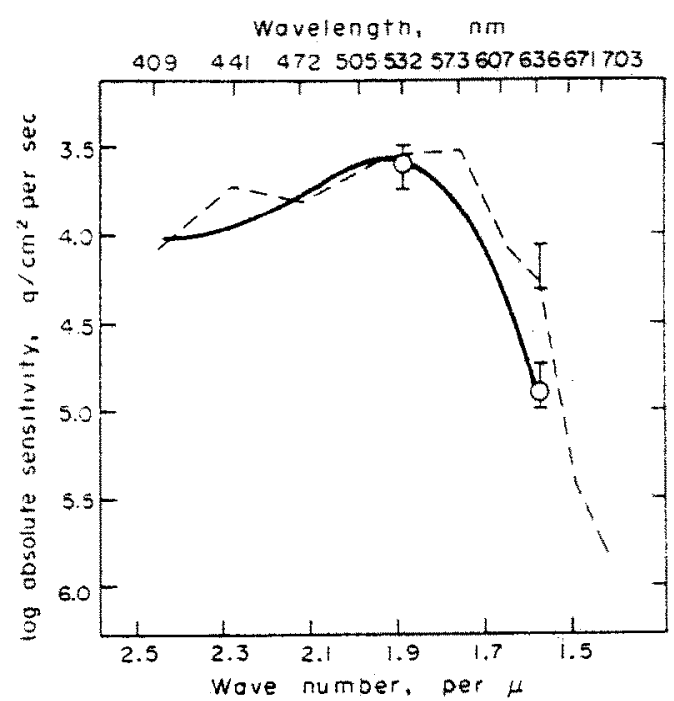

Fig. 8. The two points show mean increment thresholds for $532 \mathrm{~nm}$ and $636 \mathrm{~nm}$ tests on a $703 \mathrm{~nm}$ background for three fish. The bars indicate the range of values obtained. The dashed line, from Fig. 7, represents riean spectral sensitivity at absolute threshold; the bar at $636 \mathrm{~nm}$ indicates the range of absolute threshold values obtained at that wavelength. The smooth curve is the same porphyropsin extinction spectrum with $\lambda_{\max }=522 \mathrm{~nm}$ that appears in Fig. 7. was accompanied by large changes the relative vos. itions of the receptors.

The second experiment was histological. Three different fish were exposed, following several hours of dark adaptation, to the $703 \mathrm{~nm}$ light 1,2 or $3 . \log$ units above absolute threshold. The fish were placed in the box where behavioral tests were conducted (see Fig. 2), and their right eyes were exposed for 32-34 min. Figure 9 shows that the retina was photomechanically dark adapted until the background was $3 \mathrm{log}$ units above absolute threshold confirming the lack of photomechanical effect of the background used in the chromatic adaptation experiment. All the left eyes were photomechanically dark adapted.

Both these tests support the inference that a second mechanism, apart from the rods. mediated absolute threshold in the long wavelengths. This must be the red-sensitive cones, with $i_{\max }$ at $625 \mathrm{~nm}$

\section{Red cone threshold}

At $636 \mathrm{~nm}$. three of the subjects had nearly the same threshold, and that of the fourth was about 0.2 $\log$ units lower. This difference is within the usual range of variability (compare with Fig. 5, for example). The psychometric functions at $636 \mathrm{~nm}$ are shown in Fig 10. The mean log thrishold in terms of quanta incident per second per red cone, was. -2.35 . or 1 quantum incident per 224 red cones.

In order to estimate the number of effective quantal absorptions by the red-sensitive cones. we must take into account four factors. The first two also applied to the rods. (1) Not all quanta are caught; we assume only $50 \%$ are caught by the red cones at $636 \mathrm{~nm} .(2)$ The quanta caught are not all effective; we assume a quantum efficiency of 0.5 . (3) In the dark-adapted retina. the cone outer segments are enveloped by pigment epithelium. which has been estimated in the frog to reduce the light received by the outer segments to 0.7 of the value when the pigment is absent (Back, Donner and Reuter, 1965). We assume this same value for the goldfish. (4) In the dark-adapted retina. the outer segments of the cones are sclerad to those

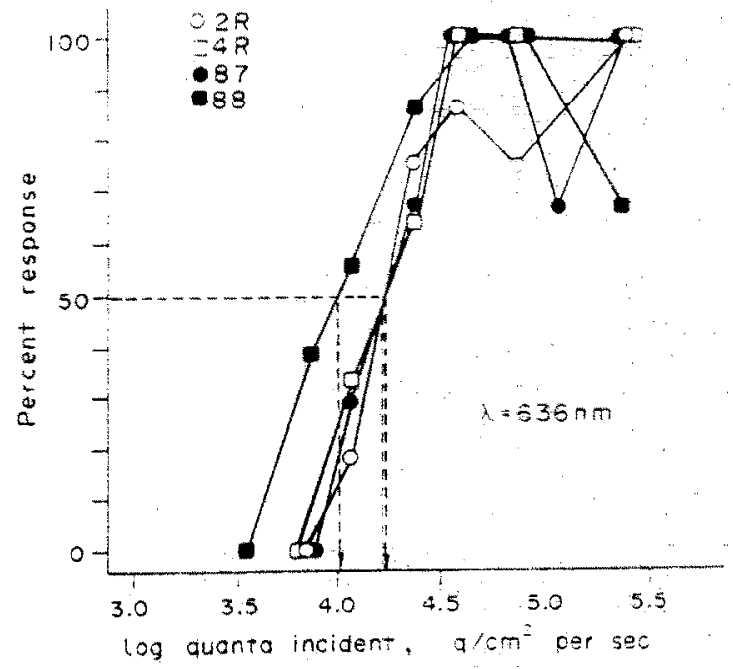

Fig 10. Absolute visual threshold at $636 \mathrm{~nm}$ obtained with respiration conditioning. The units on the abscissa are $\alpha / \mathrm{cm}^{2}$ per sec incident at the retina. 


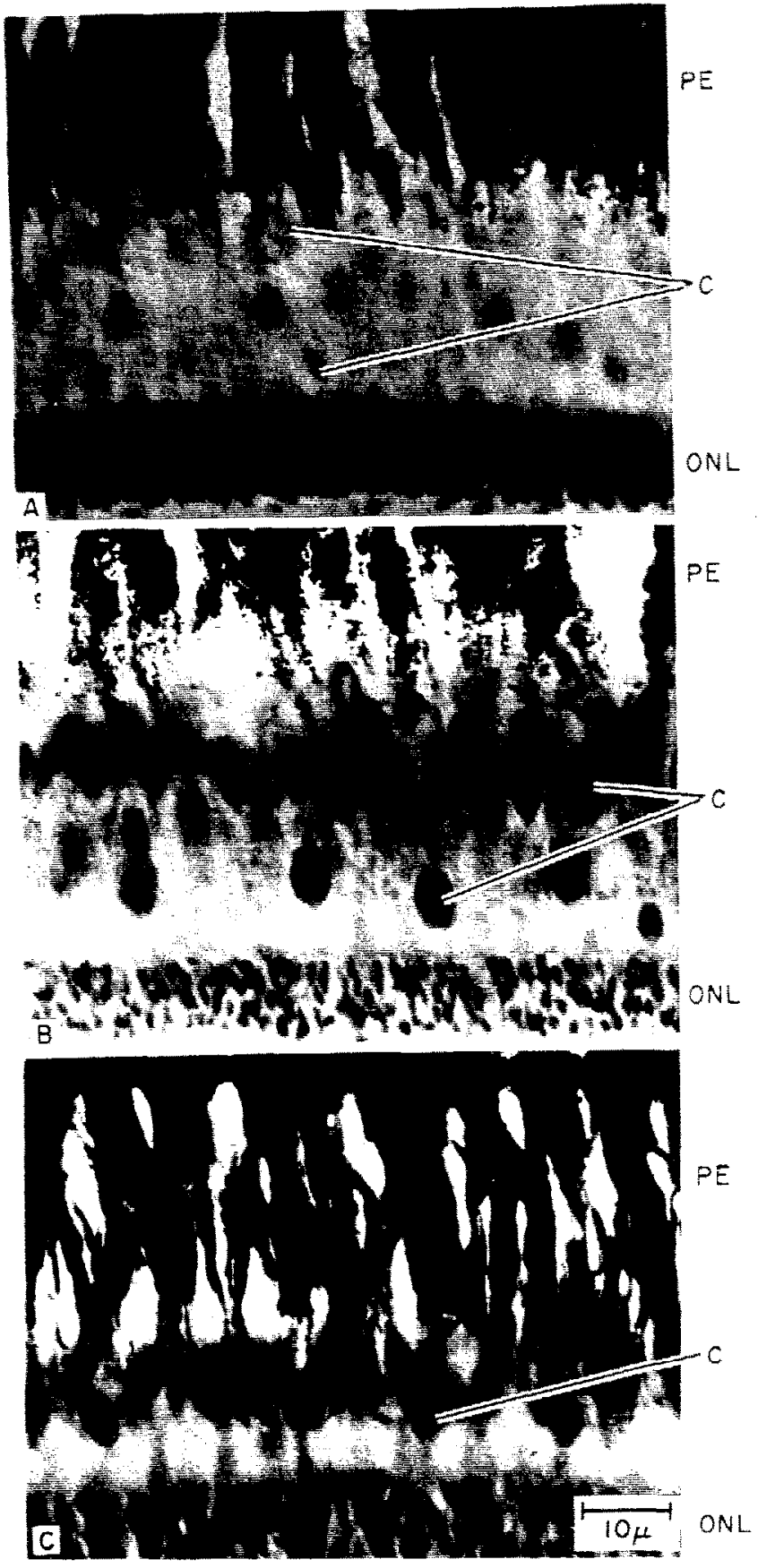

Fig. 9. Retinomotor state during chromatic adaptation tests. A. Goldfish No. 117, right eye. following $34 \mathrm{~min}$ exposure to $70, \mathrm{~nm}$ light $1 \mathrm{log}$ unit above behavioral absolute threshold for $703 \mathrm{~nm}$. B. No. 118. right eye, following $32 \mathrm{~min}$ exposure to $703 \mathrm{~nm}$ light $2 \log$ units above threshold. C. No. 119. right eve. $32 \mathrm{~min}$ at $3 \log$ units above threstold. PE: pigment epithelium: $\mathrm{C}$ : cone ellipsoids: ONL outer nuclear layer. Fish were dark adapted at least 5 hr before exposure, and their left (nonstimulated) eyes all appeared fully dark adapted. 
Table 2. Absolute threshold at $636 \mathrm{~nm}^{*}$

\begin{tabular}{lcccc}
\hline Log quanta & $\begin{array}{c}\text { Receptors per } \\
\text { incident } \\
\text { quantum } \\
\left(1 / T_{i}\right)\end{array}$ & $\begin{array}{c}\text { Receptors per } \\
\text { receptor } \\
\left(\log T_{i}\right)\end{array}$ & $\begin{array}{c}\text { Recective } \\
\text { quantum } \\
\text { least 1 } \\
\text { effective } \\
\text { quantum }\end{array}$ \\
\hline Rods & -2.90 & 794 & 45,000 & 133 \\
Red cones & -2.35 & 224 & 1280 & 164 \\
\hline
\end{tabular}

* All values refer to the first second of stimulus.

of the rods, so any light that gets to the cones must first pass through, and be attenuated by, the rods. This attenuation is very small at $636 \mathrm{~nm}$ (cf. Ebrey and Honig, 1977), and can therefore be ignored. With these assumptions, we calculate that the number of effective isomerizations was 164 . This corresponds to a quantum/red cone ratio of $1 / 1280$; that is, most red cones received no quanta, and relatively few received 1 or more. The probability of a double hit is 0.13 , or about one double hit in every eight trials. These figures are listed in Table 2, along with an estimate of the effective quantum-to-rod ratio at $636 \mathrm{~nm}$. We have already shown that the rod mechanism requires $400-830$ photoisomerizations for threshold detection near the peak of its spectral sensitivity. Because only 133 rods are stimulated at $636 \mathrm{~nm}$. our contention that another mechanism determines threshold in the long wavelengths is strengthened.

\section{DISCUSSION}

Classical conditioning of heart or respiration rate is a simple behavioral method for assessing vision in fish. The technique has been used in several different laboratories (Otis et al., 1957; McCleary and Bernstein, 1959; Hester, 1968; Schwassmann and Krag, 1970; Northmore and Yager, 1975; Powers and Easter, 1975a; Yager and Sharma, 1975; Shefner and Levine, 1976; Beauchamp and Rowe. 1977; Scott, 1977; Springer, Easter and Agranoff, 1977), but the results presented here are the first to be reported in sufficient detail to allow assessment of the method itself. We have shown that the method is very reliable; yielding very similar results in different fish and in the same fish tested over long periods of time. In fact, the variability between fish is no greater than that between human subjects (e.g. Hecht and Mandelbaum, 1939), and although the slope of the fish psychometric functions is not as steep as that of healthy humans, it is almost the same as that of subject MHP when about to become ill with influenza (see Fig. 4 in Denton and Pirenne, 1954).

\section{Absolute visual threshold}

Our values may be compared directly with work by others on fish and humans.

Raynauld (1969) determined absolute threshold of single ganglion cells in the isolated goldfish retina to light of $525 \mathrm{~nm}$. On-center cells, which were about $0.7 \mathrm{log}$ units more sensitive than off-center cells, required 1 incident quantum/sec per 15 rods for a just-detectable difference in firing rate. Although this value for threshold is more than $2 \log$ units higher than ours, the combination of a smaller stimulus $\left(22^{\circ}\right.$ diameter) and the isolated retina preparation could account for the difference.

Tavolga (1977) used a shock avoidance paradigm to determine absolute threshold to broad-band stimulation in behaving goldfish. Because the stimulus was not monochromatic and the fish was not restrained, quantitative comparisons of our thresholds with his are not possible.

Northmore (1977) has studied spatial summation at absolute threshold in goldfish, using a respiration conditioning technique similar to ours. He found that small stimuli required higher intensities than large ones, and that Ricco's law was obeyed up to $30^{\circ}$ stimulus diameter. However, some reduced area/ intensity trade-off was observed even beyond the $30^{\circ}$ critical diameter. Our results tend to support this observation because our threshold for a $132^{\circ}$ stimulus is lower than the threshold he reports for $30^{\circ}$ stimuli, and is very similar to his for a large (greater than $100^{\circ}$ diameter) stimulus (D. P. M. Northmore, personal communication).

Comparison with data from humans is necessarily more difficult, because of differences in species and technique. The report by Denton and Pirenne (1954) is most directly comparable to ours because they measured absolute thresholds for a circular, $45^{\circ}$, monochromatic $(510 \mathrm{~nm})$ stimulus, $5 \mathrm{sec}$ in duration. We have calculated that their threshold was $36,000 \mathrm{q} / \mathrm{cm}^{2}$ per sec at the comea-very close to our least sensitive value $(37,000)$ obtained with conditioned heart rate. Pupillary areas differed about 5-fold, so 18,000 quanta/sec entered the human pupil, while only 3700 entered the smaller pupil of the goldfish. Denton and Pirenne assumed that $1 / 10$ of the quanta that entered the eye were absorbed by the pigment, but they did not consider quantum effciency. If we assume a value of 0.5 , then for the human there are 900 effective photoisomerizations $/ \mathrm{sec}$ at threshold. This is very close to the value 830 from our heart rate experiment, and about twice the value obtained with respiration rate conditioning (400). We conclude that for large stimuli of long duration, the fish is at least as sensitive as the human, measured either at the cornea or at the retina.

\section{2-quantum hypothesis}

We claim that double hits occurred in only $3-13 \%$ of the trials, a frequency much too low to account for detection on $50 \%$ of the trials. Although these numbers seem to argue strongly against the 2-quantum hypothesis (Bouman and van der Velden, 1948), the argument weakens if different assumptions are made about pigment density and quantum efficiency; with higher values than the ones we used, the fre- 
quency of double hits increases, and the 2-quantum hypothesis remains possible. The spatial inhomogeneity of the beam. the slight spatial variations in receptor densities, and the effect of the tapetum lucidum (see Methods) likewise weaken our claim. However. Northmore's results on spatial summation mentioned earlier (Northmore. 1977) are not compatible with the 2-quantum hypothesis for the reasons given by Brindley (1970). It therefore seems probable that the thresholds we report are consequences of single isomerizations in a number of individual photoreceptors.

\section{Comparison of sensitivities of rods and cones}

The definition of the term "sensitivity" determines which of the two receptor types appears to be more sensitive. When the number of isomerizations per receptor is considered, rods and red cones are equally sensitive: I quantum is sufficient for each. If we consider the retinal illumination nccessary for vision. the rods are about five times more sensitive than the red cones (see Fig. 7). This difference in sensitivity to retinal illumination must be due, at least in part. to the fact that the rods occupy so much larger a proportion of the retinal surface than do the red cones (see Methods). It could also result from the higher intrinsic photosensitivity (i.e. voltage/quantum) and greater interreceptor connectivity of rods (turtle: Baylor and Hodgkin. 1973: Copenhagen and Owen. 1976: Schwartz. 1975. 1976: mudpuppy: Fain and Dowling. 1973).

The number of effective photoisomerizations necessary for vision provides yet another indicator of sensitivity, and although the result seems counterintuitive, we find that by this criterion the red cone system is at least twice as sensitive as the rod system; that is. the red cones require only 164 photoisomerizations, vs 400 for the rods. Perhaps the rod system is noisier than the red cone system. so that more rods need to be activated to provide a clear indicator of stimulus-evoked activity.

\section{Spectral sensitivity at absolute threshold}

Every previous study of the dark-adapted spectral sensitivity of the goldfish, whether electrophysiological (Jacobson, 1964; Burkhardt, 1966; Raynauld, 1969, 1972; Thorpe, 1972, 1973; van den Berg and Spekreijse, 1976) or behavioral (Ames, 1968; Yager. 1968) has shown sensitivity in the long wavelengths to be higher than predicted from the absorption spectrum of goldfish rod porphyropsin. Our measurement. which matches the spectral sensitivity of single darkadapted retinal ganglion cells (Raynauld, 1969. 1972) very well (see Fig. 1 in Powers. 1976). revealed the same heightened sensitivity in the long wavelengths. A similar deviation from a pure rod-mediated spectral sensitivity also occurs in the carp (Witkovsky. 1968) and lemon shark (Cohen, Gruber and Hamasaki. 1977). but not in the three species of marine fisties studied by Easter and Hamasaki (1973).

The results we have reported show that the goldfish's extra sensitivity in the long wavelength region is due to a second receptor mechanism-probably the red cones-which is activated at intensities below threshold for rods. Apparently, elongation of the myoid and shielding by the pigment epithelium does not prevent the cones from catching quanta when very few are available.

We condude that the goldfish remains mesopic at absolute threshold. This inference is supported by the following paper, in which we show that they can discriminate wavelengths at interisitie very close to absolute visual threshold (Powers and Easter, 1978).

Acknowledgements-Supported by PHS gant EY-00168 to S.S.E. and by graduate student research grants to M.K.P. from the Department of Psychology and the Graduate School. University of Michigan. M.K.P. was supported by predoctoral fellowships from the Gradiate School and from NIMH. We thank M. Alpern. D. R. Copenhagen. D. G. Green, R: W. Knighion and D. P. M. Northmore for helpful comments on earlier drafts and J. Easter for doing the retinal histology. The generosity of D. P. M. Northmore. who gave us advice in the use of the respir. ation conditioning technique, and of S.C. Sharma, who donated a thermistor. is gratefully acknowledged.

\section{REFERENCES}

Ali M. A. (1975) Retinomotor responses. In Vision in Fishes (edited by Ali M. A.). Plenum Press Vew York.

Ames L. L. (1968) Relative spectral sensitivity of the goldfish (Carassius auratus) obtained with a discrimination training procedure. Ph.D. dissertation. University of Maryland.

Bäck I., Donner K. O and Reuter T. $(1965)$ The screening effect of the pigment epithelium on the retinal rods in the frog. Vision Res. 5, 101-111.

Baylor D. A. and Hodgkin A. L. (19) Detection and resolution of visual stimuli by turtle photoreceptors. $J$. Physiol. 234. 163-198.

Beauchamp R. D. and Rowe J. S. (19-, Goldfish spectral sensitivity: a conditioned heart tate measure in restrained or curarized fish Vision Res 17, 617-624.

Berg T. J. T. P. van den and Spekreije H. (1976) ERG photometry in goldfish by the criterion response method. Doc. Ophthal. Proc. Ser. XIIth I.S.C.E.R.G. Simposium. pp. $183-191$.

Bouman M. A. and van der Velden H. A. (1948) The two quanta hypothesis as a general explanation for the behaviot of threshold values and visual acuity for the several receptors of the human eye. $j$ opt. Soc. 4 m. 38 . $570-581$.

Bridges C. D. B. (1967) Spectroscopic froperties of porphyropsins. Vision Res. 7, 349-369.

Brindley G. S. (1970) Physiology of the Retina and Visual Pathway, pp. 192-195. Williams \& Whkns. Batimore.

Burkhardt D. A. (1966) The goldfish electroretinogram: Relation between photopic spectral sensitivity functions and cone action spectra. Vision Res 6.517.53?

Charman W. N. and Tucker J. (1973) The optical system of the goldfish eye. Vision Res. 13, $1-8$

Cohen J. L. Gruber S. H. and Hamasaki D. I. (1977) Spec tral sensitivity and Purkinje shift in the retina of the lemon shark, Negaparion brevirostris (Poey) Vision Res. 17, 787-792.

Copenhagen D. R. and Owen W. G. 1976 , Functional characteristics of lateral interactions between rods in the tetina of the snapping turtle. J. Physiol 259. 251-28?

Crouzy R. and Ali M. A. (1965) Donnes photométriques spectrales sur l'oeil de la truite albino et sur son pigment scotopique. C.r. Acad. Sci. Paris 261. $4509-4512$.

Denton E. J. and Pirenne M. H. (1954) The absolute sensitivity and functional stability of the hutan eye. $f$. Phyt siol. $123,417-442$.

Denton E. J. Muntz W. R. A. and Notbmore D. P. M. (197!) The distribution of visual pigment within the retina in two teleosts. $J$. mar. Biol 1 sooc. 51. $905-915$ 
Easter S. S. Ir (1971) Spontaneous eye movements in restrained goldfish. Vision Res. 11, 333-342.

Easter S. S. Jr and Hamasaki D. I. (1973) Electroretinographically-determined scotopic spectral sensitivities of some marine fish. Vision Res. 13, 1175-1181.

Easter S. S. Jr. Johns P. R. and Baumann L. R. (1977) Growth of the adult goldfish eye: I. Optics. Vision Res. 17. $469-477$.

Ebrev T. G. and Honig B. (1977) New wavelength dependent visual pigment nomograms. Vision Res. 17 $147-151$.

Fain G. L. (1975) Quantum sensitivity of rods in the toad retina. Science $187,838-841$.

Fain G. L. and Dowling J. E. (1973) Intracellular recordings from single rods and cones in the mudpuppy retina. Science 180, 1178-1181.

Hecht S. und Mandelbaum J. (1939) The relation between vitamin $A$ and dark adaptation. $J$. Am. med. Assoc. 112 , 1910-1916.

Hecht S., Shlaer S. and Pirenne M. H. (1942) Energy, quanta, and vision. J. gen. Physiol. 25, 819-840.

Hester F. (1968) Visual contrast thresholds of the goldfish (Carassius auratus). Vision Res. 8, 1315-1335.

Jacobson M. (1964) Spectral sensitivity of single units in the uptic tectum of the goldfish $Q$. Jl exp. Physiol. 49 . 384-393.

Johns P. R. and Easter S. S. Jr (1977) Growth of the adult goldfish eve: II. Increase in retinal cell number. J. comp. Veurol. 176, 331-342.

Kaneko A. (1973) Receptive field organization of bipolar and amarcrine cells in the goldfish retina. J. Physiol. 235. 133-15j

Kropf A. (1967) Intramolecular energy transfer in rhodopsin. Vision Res. 7, 811-818.

Liebman P. A. and Entine G. (1964) Sensitive low-lightlevel microspectrophotometer: Detection of photosensitive pigments of retinal cones. J. opt. Soc. Am. 54. $1451-1459$.

Marc R. E. and Sperling H. G. (1976) The chromatic organization of the goldfish conc mosaic. Vision Res. 16. $1211-1227$

Marks W. B. (1965) Visual pigments of single goldfish cones. J. Physiol. 178, 14-32.

McCleary R. A. and Bernstein J. J. (1959) A unique method for control of brightness cues in study of color vision in fish. Physiol. Zool. 32. 284-292.

Miller W. H. and Snyder A. W. (1972) Optical function of myoids. Vision Res. 12. 1841-1848.

Northmore D. P. M. (1977) Spatial summation and light adaptation in the goldfish visual system. Nature $\mathbf{2 6 8}$ $450-451$

Northmore D. P. M. and Yager D. (1975) Psychophysica methods for investigations of vision in fishes. In Vision in Fishes ledited by Ali .M. A.). Plenum Press, New York.

Otis L. S., Cerf J. A. and Thomas G. J. (1957) Conditioned inhibition of respiration and heart rate in the goldfish. Science 126, 263-264.

Powers M. K. (1976) Behaviorally measured spectral sensitivities of the goldfish match physiological predictions. Neurosci. Abstr. 2, 1084.

Powers M. K. (1977) Visual sensitivity of the goldfish. Ph.D. dissertation, University of Michigan.

Powers M. K. and Easter S. S. Jr (1975a) A behavioural test of rod-red cone convergence in the goldfish retina.
In Vision in Fishes (edited by Ali M. A.). Plenum Press New York.

Powers M. K. and Easter S. S. Jr (1975b) Absolute visual threshold in the goldfish obtained by classical conditioning. Neurosci. Abstr. 1. 522.

Powers M. K. and Easter S. S. Jr (1978) Wavelength diserimination by the goldfish near absolute visual threshold. This issue. pp. 1149-1154.

Raynauld J. P. (1969) Rod and cone responses of ganglion cells in goldfish retina: A microelectrode study. Ph.D. dissertation, Johns Hopkins University.

Raynauld J. P. (1972) Goldfish retina: Sign of the rod input in opponent color ganglion cells. Science 177, 84-85.

Schellart N. A. M. (1973) Dynamics and statistics of photopic ganglion cell responses in isolated goldfish retina. Ph.D. thesis, University of Amsterdam.

Schwanzara S. A. (1967) The visual pigments of freshwater fishes. Vision Res. 7. 121-148.

Schwartz E. A. (1975) Cones excite rods in the retina of the turtle. J. Physiol. 246, 639-651.

Schwartz E. A. (1976) Electrical properties of the rod syncytium in the retina of the turtle. J. Phusiol. 257. 379-406.

Schwassmann H. O. and Krag M. H. (1970) The relation of visual field defects to retinotectal topography in teleost fish. Vision Res. 10, 29-42.

Scott M. Y. (1977) Behavioral tests of compression of retinotectal projection after partial tectal ablation in goldfish. Expl Neurol. 54, 579-590

Shefner J. M. and Levine M. W. (1976) A psychophysical demonstration of goldfish trichromacy. Vision Res. 16. 671-673.

Springer A. D., Easter S. S. Jr and Agranoff B. W. (1977) The role of the optic tectum in various visually-mediated behaviors of goldfish. Brain Res. 128. 393-40-4.

Stell W. K. and Hárosi F. I. (1976) Cone structure and visual pigment content in the retina of the goldfish. Vision Res. 16, 647-657.

Tavolga W. N. (1977) Behavioral thresholds for diffuse illumination in the goldfish. J. exp. Biol. 67, 89-96.

Thorpe S. A. (1972) The effect of chromatic adaptation and temperature on the spectral sensitivity of the gold fish. Carassius auratus. Ph.D. dissertation. Brown University.

Thorpe S. A. (1973) The effects of temperature on the psychophysical and electroretinographic spectral sensitivity of the chromatically-adapted goldfish. Vision Res. 13 . $59-72$.

Tomita T. Kaneko A. Murakami M. and Paulter E. L. (1967) Spectral response curves of single cones in the carp. Vision Res. 7, 519-531.

Wagner H. G., MacNichol E. F. Jr and Wolbarsht M L. (1960) The response properties of single ganglion cells in the goldfish retina. J. gen. Physiol. 43, 45-62.

Witkovsky P. (1968) The effect of chromatic adaptation on color sensitivity of the carp electroretinogram. Vision Res. 8. 823-837.

Yager D. (1967) Behavioral measures and theoretical analysis of spectral sensitivity and spectral saturation in the goldfish, Carassius auratus. Vision Res. 7, 707-727.

Yager D. (1968) Behavioural measures of the spectral sensitivity of the dark-adapted goldfish. Nature 220 . $1052-1053$.

Yager D. and Sharma S. C. (1975) Evidence for visual function mediated by anomalous projection in goldfish. Nature 256, 490-491. 